\title{
СРАВНИТЕЛЬНЫЙ АНАЛИЗ РЕЗУЛЬТАТОВ ИССЛЕДОВАНИЯ КОМПЬЮТЕРНОЙ МОДЕЛИ СОЛНЕЧНОГО КОЛЛЕКТОРА С РЕЗУЛЬТАТАМИ РАСЧЕТА ПО ПРЕДЛОЖЕННОЙ МЕТОДИКЕ
}

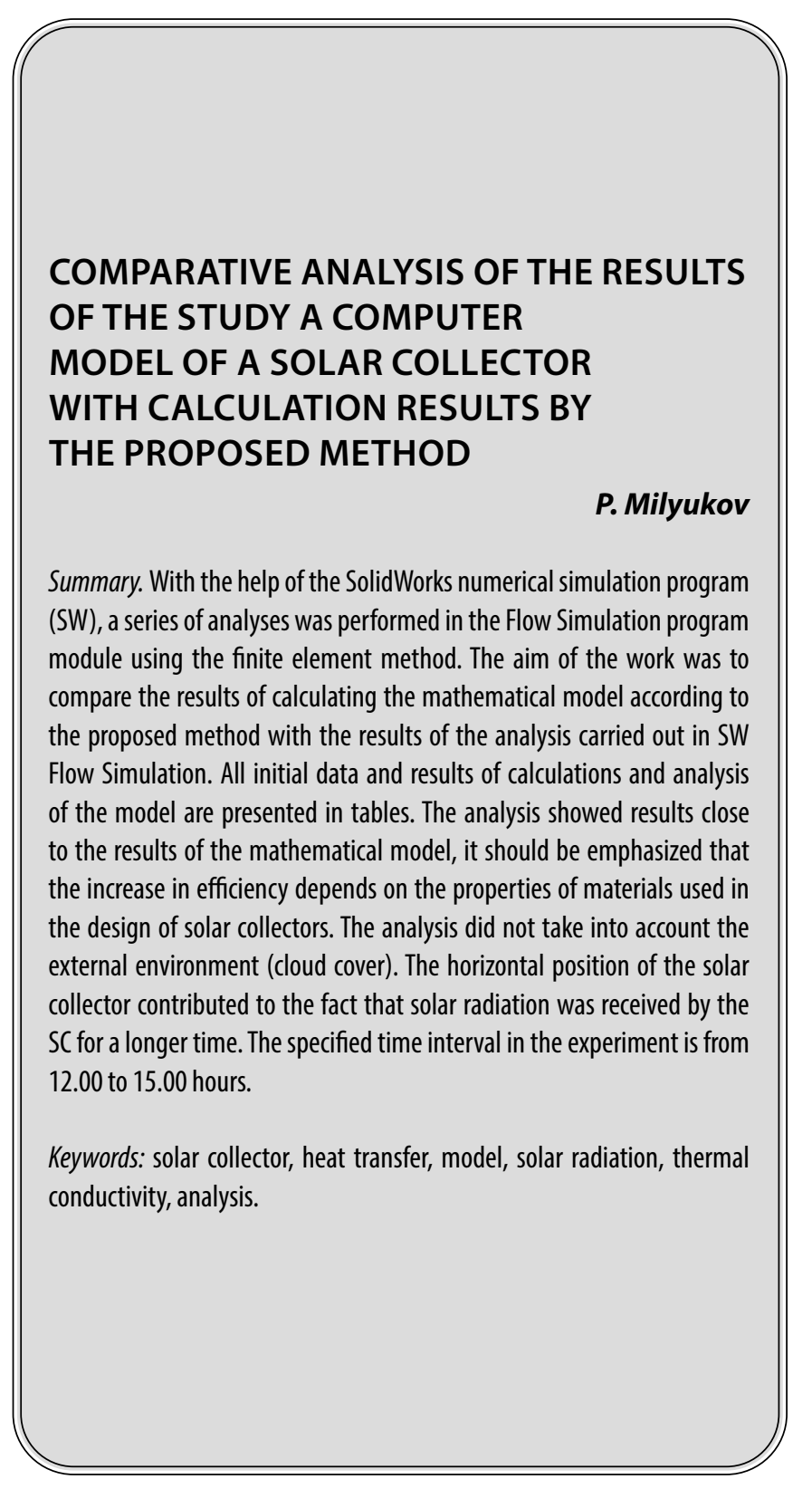

o дним из наиболее эффективных приборов, преобразующих солнечную энергию, является солнечный коллектор, который преобразовывает солнечное излучение в тепловую энергию для использования в коммунальных и бытовых нуждах населения. Может использоваться как основной или дополнительный нагреватель в системе горячего водоснабжения.
Милюков Павел Александрович

Преподаватель, Тихоокеанский государственный университет, г. Хабаровск Pavel-milukov@mail.ru

Аннотация. С помощью программы численного моделирования SolidWorks (SW) было проведена серия анализов в модуле программы Flow Simulation методом конечных элементов. Целью работы являлось, сравнить результаты расчета математической модели по предложенной методике, с результатами анализа, проводимого в SW Flow Simulation. Все исходные данные и результаты проводимых подсчетов, и анализа над моделью, представлены в таблицах. Анализ показал результаты близкие к результатам математической модели, нужно подчеркнуть, что повышение КПД зависит от свойств материалов, используемых в проектировании солнечных коллекторов. В анализе не учитывалась внешняя среда (облачность). Горизонтальное положение солнечного коллектора способствовало тому, что солнечное излучение принималось СК в течение большего времени. Заданный временной отрезок в эксперименте с 12.00 до 15.00 часов.

Ключевые слова: солнечный коллектор, теплообмен, модель, солнечное излучение, теплопроводностью, анализ.

Предлагаемое конструкционное решение плоского солнечного коллектора (ПСК) упрощенно (рис. 1).

1. Корпус (алюминий, $\delta=2$ мм);

2. Стекло с высокой пропускной способностью;

3. Стекло с высокой пропускной способностью;

4. Абсорбер (медь) с покрытием, имеющим высокое светопоглощение; 
Таблица 1. Общие характеристики

\begin{tabular}{|c|c|}
\hline Название & Параметры \\
\hline Общая площадь & $2.42 \mathrm{~m} 2$ \\
\hline Рабочая площадь & $2.15 \mathrm{~m} 2$ \\
\hline Длина & $2.226 \mathrm{~mm}$ \\
\hline Ширина & $1.084 \mathrm{MM}$ \\
\hline Высота & $112 \mathrm{MM}$ \\
\hline Объем змеевика коллектора & 0.42 л \\
\hline Материал абсорбера & $\mathrm{Cu}$ \\
\hline Вес (пустой) & $\approx 43 \mathrm{k \Gamma}$ \\
\hline Проходное сечение патрубков & $23 \mathrm{Mm}$ \\
\hline Толщина ударопрочного стекла & $3.2 \mathrm{MM}$ \\
\hline Пропускная способность стекла & $91 \%$ \\
\hline Абсорбция & $95 \%$ \\
\hline Эмиссия & $5 \%$ \\
\hline
\end{tabular}

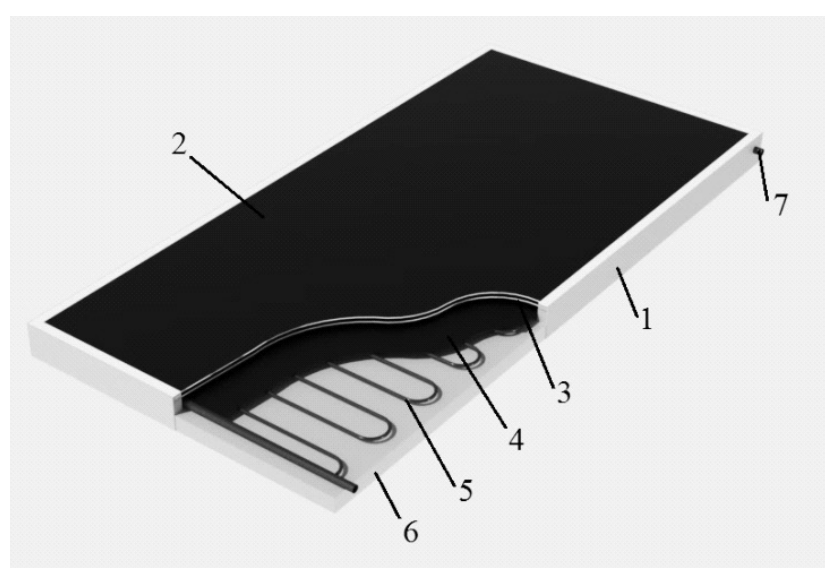

Рис. 1. Общий вид солнечного плоского коллектора

5. Теплоотводящая трубка коллектора (медь, Ø9 мм);

6. Теплоизоляция (50 мм);

7. Магистраль (медь, Ø23 мм).

Заявленная конструкция солнечного коллектора представлена по индивидуальным размерам, содержащая корпус, в котором размещен поглощающий элемент с хорошей теплопроводностью, абсорбер, представляющий собой лист металла. Абсорбер связан с теплопроводящей системой в виде трубчатого змеевика, и плотно прилегает к боковой теплоизоляции (слева, справа) для уменьшения конвективного теплообмена между абсорбером и внутренним стеклом. Также в конструкцию входит прозрачный элемент (два закаленных стекла с высокой пропускной способностью, с расстоянием друг от друга 11.8 мм). Внутри корпуса размещена термостойкая вспененная теплоизоляция с малой теплопроводностью.

Модель солнечного термального коллектора основана на системе балансовых уравнений тепловых потоков в коллекторе, возникающих из-за поступления солнеч- ного излучения в коллектор, отвода тепла теплоносителем и рассеяния (потерь) тепла в окружающее пространство.

Количество тепла, поступающего от солнечного излучения через двойное остекление коллектора, определяется соотношением

$$
Q_{\text {солн }}=q S \tau
$$

где: $q, B m /\left(\mathcal{M}^{2} \cdot c\right)$ - тепловой поток, попадающий на пластину термального солнечного коллектора;

$S=a b, M^{2}$ - площадь пластины ( $a, b$ - длина и ширина пластины соответственно);

$\tau, c$ - время нагрева пластины.

Величина теплового потока с учетом эффектов пропускания, отражения и поглощения теплового излучения при прохождении через двойное остекление определяется соотношением (при отсутствии поглощения излучения остеклением) 
Таблица 2. Исходные данные для расчета

\begin{tabular}{|c|c|c|}
\hline \multirow{2}{*}{ Наименование, характеристики } & \multicolumn{2}{|l|}{15.07} \\
\hline & Ha 12:00 & Ha 15:00 \\
\hline $\begin{array}{l}\text { 1. Геометрические характеристики солнечного коллектора (рабочая площадь) } \\
\text { А). Высота, } \boldsymbol{a}, \boldsymbol{M} \\
\text { Б). Ширина, } \boldsymbol{b}, \boldsymbol{M} \\
\text { В). Площадь, } \boldsymbol{M}^{2} \\
\mathrm{~S}=\mathrm{a} \cdot \mathrm{b}\end{array}$ & \multicolumn{2}{|l|}{$\begin{array}{l}2,1125 \\
1,020 \\
2,15475\end{array}$} \\
\hline 2. Общее время инсоляции т, $c$ & 10800 & 10800 \\
\hline 3. Внутренний диаметр трубопровода $d, \boldsymbol{M}$ & \multicolumn{2}{|l|}{0,009} \\
\hline $\begin{array}{l}\text { 4. Массовый расход теплоносителя (вода), } \\
\mathrm{G}, \mathrm{k} / / \mathrm{c} \\
\mathrm{G}=\mathrm{V} / \mathrm{\tau}\end{array}$ & $\begin{array}{l}0.006944444 \\
(25 / 3600)\end{array}$ & 0.006944444 \\
\hline $\begin{array}{l}\text { 5. Характеристики теплоизоляционного материала } \\
\text { А). Материал } \\
\text { Б). Толщина } \delta_{\text {изол }}, \boldsymbol{M}\end{array}$ & \multicolumn{2}{|c|}{$\begin{array}{l}\text { вспененный каучук, термический } \\
\text { 0,05 }\end{array}$} \\
\hline $\begin{array}{l}\text { 6. Характеристики стекла } \\
\text { А). Тип } \\
\text { Б). Толщина, } \delta_{c m}, \boldsymbol{M}\end{array}$ & \multicolumn{2}{|c|}{$\begin{array}{l}\text { Боросиликатное, закаленное, структурированное, } \\
\text { 0,0032 }\end{array}$} \\
\hline $\begin{array}{l}\text { 7. Характеристика воздушной прослойки } \\
\text { А). } 1 \text { толщина } \delta_{\text {возд }}, \boldsymbol{M} \\
\text { Б). } 2 \text { толщина } \delta_{\text {возд }} \boldsymbol{M}\end{array}$ & \multicolumn{2}{|l|}{0,0118} \\
\hline $\begin{array}{l}\text { 8. Характеристики пластины коллектора } \\
\text { А). Тип } \\
\text { Б). Толщина, } \boldsymbol{M} \\
\text { В). Температура плавления, } K\end{array}$ & \multicolumn{2}{|l|}{$\begin{array}{l}\mathrm{Cu} \\
0,026 \\
1356,2\end{array}$} \\
\hline
\end{tabular}

Таблица 3. Табличные данные для расчета

\begin{tabular}{|c|c|c|}
\hline \multirow{2}{*}{ Наименование, характеристики } & \multicolumn{2}{|l|}{15.07} \\
\hline & Ha 12:00 & Ha 15:00 \\
\hline \multirow{2}{*}{$\begin{array}{l}\text { 1. Характеристики стекла: } \\
\text { А). } R \text { - коэффициент отражения защитного стекла } \\
\text { Б). Средняя величина } \\
\text { Источник данных: [5], [6], [7] }\end{array}$} & 0,0987 & 0,0804 \\
\hline & \multicolumn{2}{|l|}{0,0896} \\
\hline $\begin{array}{l}\text { 2. Среднемесячная температура воздуха, } t^{\circ}{ }^{\circ} \mathrm{C} \\
\text { Источник данных: [8] }\end{array}$ & \multicolumn{2}{|l|}{$+21,1$} \\
\hline $\begin{array}{l}\text { 3. Характеристики теплоносителя: } \\
\text { А). Тип } \\
\text { Б). Удельная теплоемкость } c, \partial ж /(\kappa 2 \cdot г р а д) \\
\end{array}$ & \multicolumn{2}{|l|}{$\begin{array}{l}\text { Вода } \\
\approx 4200\end{array}$} \\
\hline $\begin{array}{l}\text { 5. Характеристики теплоизоляционного материала } \\
\text { А). Теплопроводность } \lambda, B m /(\boldsymbol{M} \cdot K) \\
\text { Источник данных: [9] }\end{array}$ & \multicolumn{2}{|l|}{0,033} \\
\hline $\begin{array}{l}\text { 6. Характеристики стекла } \\
\text { А). Теплопроводность, } \lambda, B m /(\boldsymbol{M} \cdot K) \\
\text { Источник данных: [10] }\end{array}$ & \multicolumn{2}{|l|}{0,142} \\
\hline $\begin{array}{l}\text { 7. Характеристика воздушной прослойки } \\
\text { А). Теплопроводность, } \lambda, B m /(\mathcal{M} \cdot K) \\
\text { Б). Теплопроводность, } \lambda, B m /(\mathcal{M} \cdot K) \\
\text { Источник данных: [11] }\end{array}$ & \multicolumn{2}{|l|}{0,0268} \\
\hline $\begin{array}{l}\text { 8. Характеристики пластины коллектора } \\
\text { А). Коэффициент поглощения пластины є термального коллектора, } A \\
\text { Источник данных: [5] }\end{array}$ & \multicolumn{2}{|l|}{0,95} \\
\hline $\begin{array}{l}\text { 9. Плотность теплового потока солнечного излучения, } q_{\text {соль }}, \mathrm{Bm} /\left(\mathrm{M}^{2} \cdot \mathrm{c}\right) \\
\text { Источник данных: [12] }\end{array}$ & \multicolumn{2}{|l|}{878} \\
\hline
\end{tabular}


Таблица 4. Результаты расчета

\begin{tabular}{|c|c|c|}
\hline \multirow{2}{*}{ Наименование характеристики } & \multicolumn{2}{|l|}{ Для 15.07} \\
\hline & Ha 12:00 & Ha 15:00 \\
\hline $\begin{array}{l}\text { 1. Количество тепла, поступающего от солнечного излучения } \\
Q_{\text {соли }}=q S \tau \\
\text { (Формула 1) } \\
\text { Средняя величина }\end{array}$ & \multicolumn{2}{|l|}{$16,3 \cdot 10^{6}$} \\
\hline \multirow{2}{*}{$\begin{array}{l}\text { 2. Величина теплового потока, } B m /\left(M^{2} \cdot c\right) \\
q=q_{\text {солн }} \cdot(1-R)^{2} \cdot(1+R 2) \cdot A \\
\text { (Формула 2) } \\
\text { Средняя величина }\end{array}$} & 696,3130 & 709,9281 \\
\hline & \multicolumn{2}{|l|}{703,0911} \\
\hline $\begin{array}{l}\text { 3. Тепловые потери в солнечном термальном коллекторе вследствие } \\
\text { собственного излучения } \\
Q_{\text {изл. коллект }}=S \sigma t_{\text {коллектора }}{ }^{4} \tau(1-R A) \\
\text { (Формула 3) }\end{array}$ & \multicolumn{2}{|l|}{1698,170683} \\
\hline $\begin{array}{l}\text { 4. Тепловые потери вследствие механизма теплопроводности через остекление } \\
\text { (включая имеющиеся воздушные зазоры) } \\
Q_{\text {остекл }}=S \cdot \frac{t_{\text {коллектора }}-t_{\text {окр }}}{\sum_{i=1}^{i=1} \frac{\delta_{i}}{\lambda_{i}}} \tau, \\
\text { (Формула 4) }\end{array}$ & \multicolumn{2}{|l|}{$2,57 \cdot 10^{5}$} \\
\hline $\begin{array}{l}\text { 5. Тепловые потери вследствие механизма теплопроводности через } \\
\text { теплоизолирующую подложку с обратной стороны коллектора } \\
Q_{\text {изол }}=S \frac{\lambda_{\text {изол }} \cdot\left(t_{\text {коллектора }}-t_{\text {окр }}\right)}{\delta_{\text {изол }}} \tau \\
\text { (Формула 5) }\end{array}$ & \multicolumn{2}{|l|}{$1,24 \cdot 10^{5}$} \\
\hline $\begin{array}{l}\text { 6. Количество тепла, передаваемое теплоносителя за время работы коллектора } \\
Q_{\text {теплоносителя }}=Q_{\text {солн }}-Q_{\text {изл. коллект }}-Q_{\text {остекл }}-Q_{\text {изол' }} \\
\text { (Формула 6) }\end{array}$ & \multicolumn{2}{|l|}{$1,56 \cdot 10^{7}$} \\
\hline $\begin{array}{l}\text { 7. Повышение температуры теплоносителя при работе коллектора, } \\
\Delta t=\frac{Q_{\text {теплоносителя }}}{G \tau \mathrm{c}} \\
\text { (Формула 7) }\end{array}$ & \multicolumn{2}{|l|}{49,8} \\
\hline $\begin{array}{l}\text { 8. Характеристики пластины коллектора. } \\
\text { Коэффициент поглощения пластины є термального коллектора, } A\end{array}$ & \multicolumn{2}{|l|}{0,95} \\
\hline
\end{tabular}

$$
q=q_{\text {солн }}(1-R)^{2}\left(1+R^{2}\right) A
$$

где: $q_{\text {соли }} \mathrm{Bm} /\left(\mathrm{M}^{2} \cdot \mathrm{c}\right)$ - плотность теплового потока солнечного излучения;

$R$ - коэффициент отражения защитного стекла;

$A$ - коэффициент поглощения пластины термального коллектора.

Коэффициенты отражения и поглощения для различных материалов приводятся в справочной литературе [1]. Плотность теплового потока солнечного излучения для заданных географической широты и климатических условий определяется по справочным таблицам [2, 3].
Тепловые потери в солнечном термальном коллекторе вследствие собственного излучения коллектора и механизма теплопроводности через двойное остекление (включая имеющиеся воздушные зазоры) и теплоизолирующую подложку с обратной стороны коллектора определяются следующими соотношениями:

$$
Q_{\text {изл колл }}=S \sigma t_{\text {колл }}{ }^{4} \tau(1-R A),
$$

где: $\sigma=5,67 \cdot 108$ - постоянная Стефана-Больцмана; $t_{\text {колл }}$ - температура пластины коллектора,

$$
Q_{\text {остекл }}=S \cdot \frac{t_{\text {коллектора }}-t_{\text {окр }}}{\sum_{i=1}^{i=n} \frac{\delta_{i}}{\lambda_{i}}} \tau,
$$


Таблица 5. Постановка задачи в Flow Simulation

\begin{tabular}{|c|c|c|}
\hline \multicolumn{3}{|l|}{ Входные данные } \\
\hline Общие настройки & \multicolumn{2}{|l|}{ Заданные параметры } \\
\hline Тип задачи & $\begin{array}{l}\text { Внешняя: } \\
\text { Теплопроводность в твердых телах; } \\
\text { Радиационный теплообмен: } \\
\text { Солнечное излучение } \\
\text { Определено место положение и время г. Хабаровска } \\
\text { Нестационарность } \\
\text { Гравитация }\end{array}$ & $\begin{array}{l}+21,1 \\
48^{\circ} 29^{\prime} \\
6: 00: 00\end{array}$ \\
\hline Текучая среда & Вода, газы & \\
\hline Материал & Заданы свойства материалов & $\begin{array}{l}\text { Корпус } \\
\text { Утеплитель }\end{array}$ \\
\hline Изначальные условия & $\begin{array}{l}\text { Давление } 101325 \Pi a \\
\text { Начальная } t 0^{\circ} \mathrm{C}\end{array}$ & \\
\hline Граничные условия & $\begin{array}{l}\text { Массовый расход на входе } \\
\text { Давление окружающей среды }\end{array}$ & $\begin{array}{l}25 \pi / 4 \\
101325 \Pi a\end{array}$ \\
\hline $\begin{array}{l}\text { Поверхности } \\
\text { радиационного } \\
\text { теплообмена }\end{array}$ & Абсорбер & $95 \%$ \\
\hline Цели & Температура окружающей среды, твердого тела & \\
\hline Сетка & Ручная настройка & 2.336 .629 ячеек \\
\hline \multicolumn{3}{|c|}{ Опции управления расчетом } \\
\hline Условия завершения & $\begin{array}{l}\text { Сходимость целей } \\
\text { Итерации }\end{array}$ & 112 \\
\hline Настройка шага & $\begin{array}{l}\text { Шаг по времени } \\
\text { Длительность }\end{array}$ & $\begin{array}{l}1800 s \\
56 y\end{array}$ \\
\hline Прочее & $\begin{array}{l}\text { Положение СК } \\
\text { Физическое время расчета }\end{array}$ & $\begin{array}{l}\text { Горизонтальное } \\
5,52 \boldsymbol{\varphi}\end{array}$ \\
\hline
\end{tabular}

где: $t_{\text {колл }}$ и $t_{\text {окр }}{ }^{\circ} \mathrm{C}$ - температуры пластины коллектора и окружающей среды соответственно;

$\delta i, \mu$ - толщины стекол и воздушных прослоек в термальном коллекторе;

$\lambda i, B m /(\mathcal{M} \cdot K)$ - теплопроводности стекла и воздуха (считаются постоянными в рабочем диапазоне температур термального коллектора) и

$$
Q_{\text {изол }}=S \frac{\lambda_{\text {изол' }}\left(t_{\text {колл }}-t_{\text {окр }}\right)}{\delta_{\text {изол }}} \tau,
$$

где: ठизол, $\boldsymbol{M}$ - толщина теплоизолирующего материала в термальном коллекторе;

$\lambda_{\text {изл }} \mathrm{Bm} /(\boldsymbol{M} \cdot \mathrm{K})$ - теплопроводность теплоизолирующего материала (считается постоянной в рабочем диапазоне температур термального коллектора).

Таким образом, количество тепла за время работы коллектора, передаваемое теплоносителю определяется соотношением: 


\section{Результаты анализа в SolidWorks}

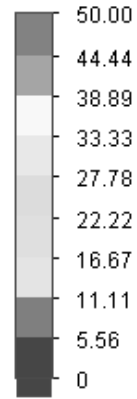

Температура (текуая среда) [ $\left.{ }^{\circ} \mathrm{C}\right]$

Картина в сечении 1: заливка Картина на поверхности 1: заливка Траектории потока 1

Траектории потока 2

Траектории потока 3

Траектории потока 4

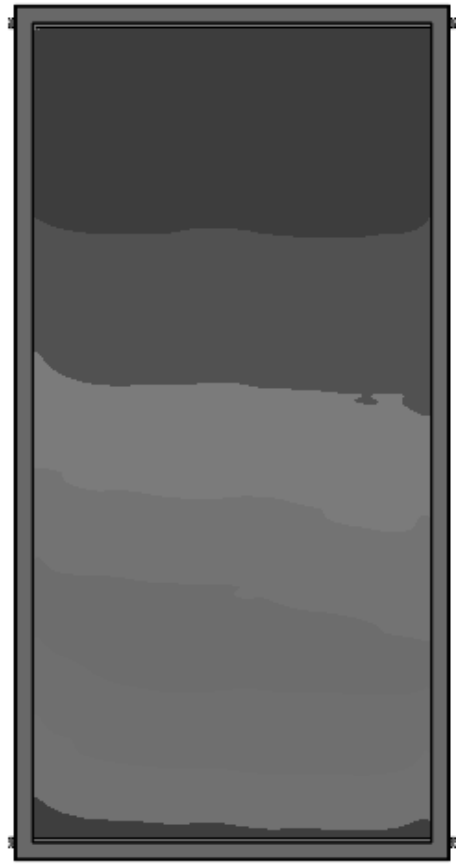

Рис. 2. Температура пластины

Температура (текучая среда) $\left[{ }^{\circ} \mathrm{C}\right]$

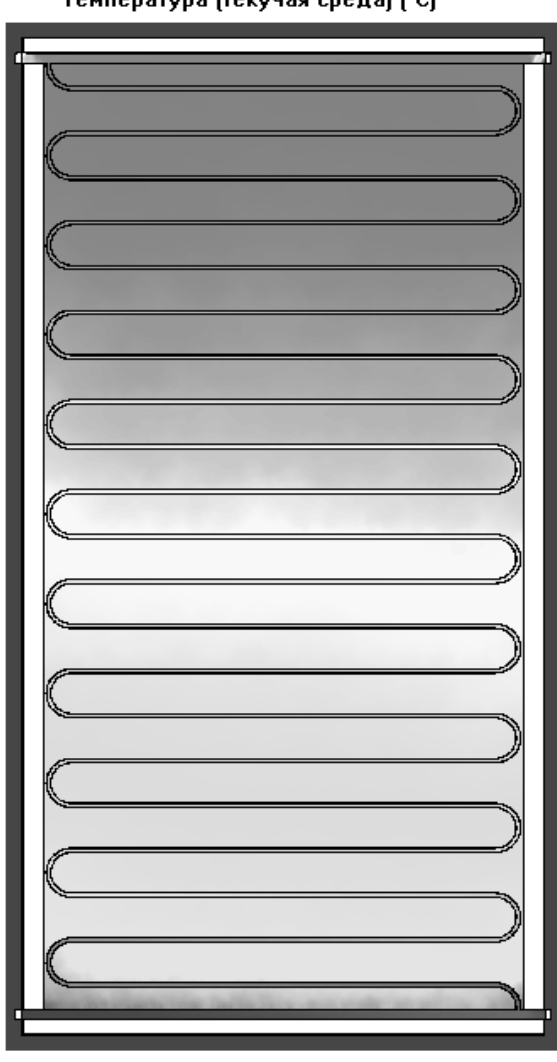

Min $=-0.122831{ }^{\circ} \mathrm{C} \quad \operatorname{Max}=48.6287^{\circ} \mathrm{C}$

Итерация $=112$

Время $=201600 \mathrm{~s}$

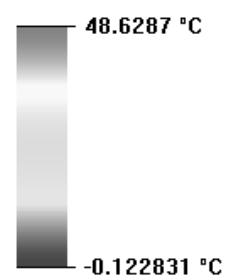

$-0.122831^{\circ} \mathrm{C}$

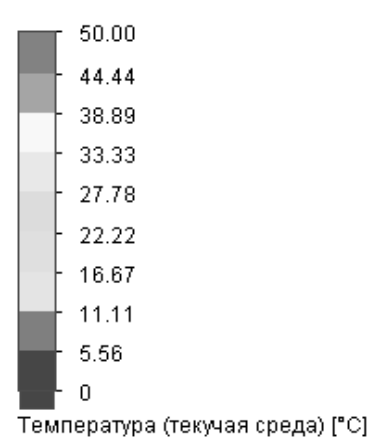

пература (текуая среда) ['c)

Картина в сечении 1: заливка

Картина на поверхности 1: заливка

Траектории потока 1

Траектории потока 2

Траектории потока 3

Траектории потока 4

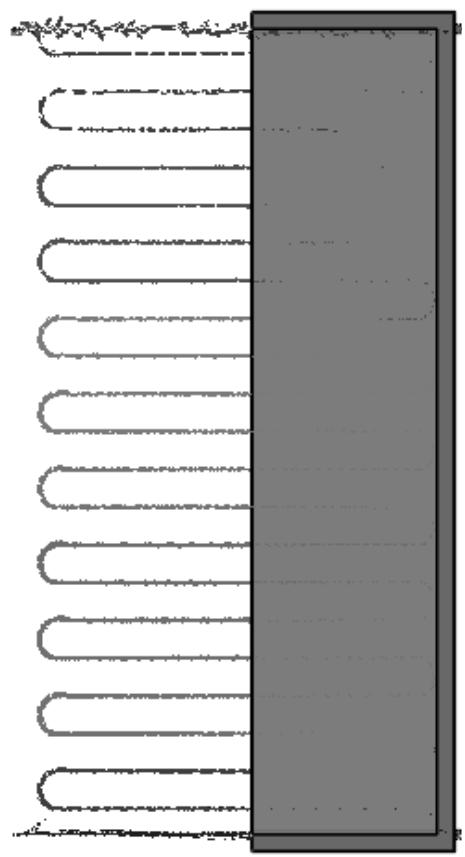

Рис. 3. Движение текучей среды

Температура [твердое тело] $\left[{ }^{\circ} \mathrm{C}\right]$
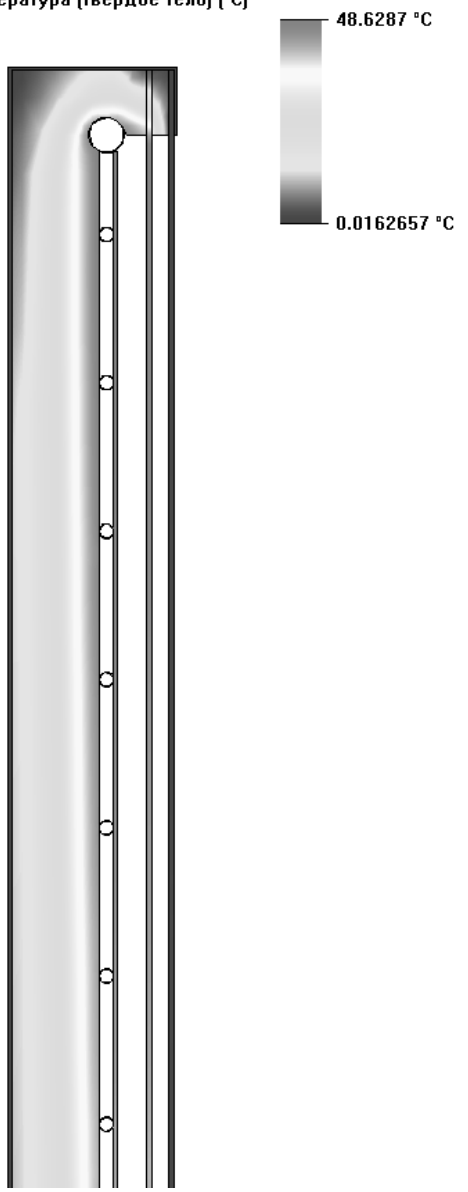

Рис. 5. Температура (текучая среда) (твердое тело) 
Таблица 6. Локальные параметры

Локальный параметр пластины

\begin{tabular}{|l|l|l|l|}
\hline Локальный параметр & Минимум & Максимум & Среднее \\
\hline Температура (твердое тело) $\left[{ }^{\circ} \mathrm{C}\right]$ & 4,939504443 & 48,62872591 & 34,42176794 \\
\hline Локальный параметр воды & &
\end{tabular}

Локальный параметр воды

\begin{tabular}{|l|l|l|l|}
\hline Локальный параметр & Минимум & Максимум & Среднее \\
\hline Удельная теплоемкость (Ср) $\left[\mathrm{J} /\left(\mathrm{kg}^{*} \mathrm{~K}\right)\right]$ & 4179,500003 & 4219,582819 & 4183,645835 \\
\hline Температура (текучая среда) $\left[{ }^{\circ} \mathrm{C}\right]$ & 0,119372754 & 48,4281393 & 32,48898814
\end{tabular}

Локальный параметр внешнего стекла

\begin{tabular}{|l|l|l|l|}
\hline Локальный параметр & Минимум & Максимум & Среднее \\
\hline Коэффициент теплоотдачи $[\mathrm{W} / \mathrm{m} \wedge 2 / \mathrm{K}]$ & 0,008215388 & 14,58069146 & 3,75664214 \\
\hline Температура (твердое тело) $\left[{ }^{\circ} \mathrm{C}\right]$ & 0,061489707 & 4,832941766 & 0,491262188 \\
\hline Коэффициент теплопроводности текучей среды $[\mathrm{W} /(\mathrm{m} * \mathrm{~K})]$ & 0,024376999 & 0,563771968 & 0,29318266 \\
Локальный параметр внутреннего стекла & & \\
\hline
\end{tabular}

\section{Локальный параметр внутреннего стекла}

\begin{tabular}{|l|l|l|l|}
\hline Локальный параметр & Минимум & Максимум & Среднее \\
\hline Коэффициент теплоотдачи $\left[\mathrm{W} / \mathrm{m}^{\wedge}\right.$ 2/K] & 0,000768257 & 191067,9059 & 24,58125877 \\
\hline Температура (твердое тело) $\left[{ }^{\circ} \mathrm{C}\right]$ & 0,064710923 & 47,79497836 & 31,34859404 \\
\hline Коэффициент теплопроводности текучей среды $\left[\mathrm{W} /\left(\mathrm{m}^{*} \mathrm{~K}\right)\right]$ & 0,024659668 & 0,640923022 & 0,323476248 \\
\hline
\end{tabular}

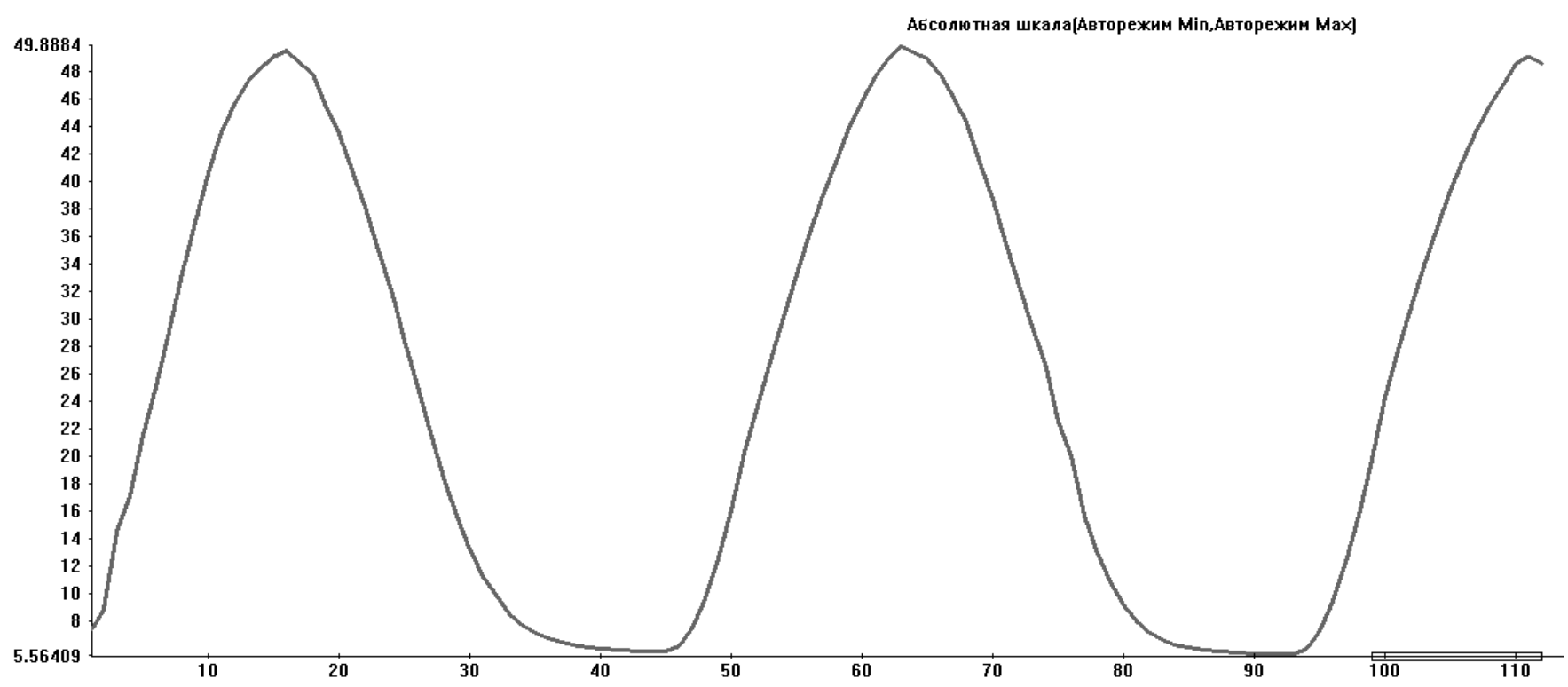

Рис. 6. Динамика температуры теплоносителя

$$
Q_{\text {теплон }}=Q_{\text {солн }}-Q_{\text {изл колл }}-Q_{\text {ост }}-Q_{\text {изол }}
$$

Повышение температуры теплоносителя при работе солнечного термального коллектора определяется следующим соотношением

$$
\Delta t=\frac{Q_{\text {теплон }}}{G \tau c} \tau
$$

где: $G, \kappa 2 / c-$ массовый расход теплоносителя; c, Дж/(кг·град) - удельная теплоемкость теплоносителя.

Следовательно, на стационарном режиме работы температура коллектора будет превышать температуру окружающей среды на величину, определяемую соотношением: [4].

$$
d Q_{x l}=d Q_{x}-d Q_{x+d x}
$$




\section{ЛИТЕРАТУРА}

1. СП 23-10-2004. Свод правил по проектированию и строительству. Проектирование тепловой защиты зданий.

2. СНиП 23-01-99. Строительные нормы и правила. Строительная климатология.

3. Идельчик, И. Е. Справочник по гидравлическим сопротивлениям / И. Е. Идельчик.- М.: Машиностроение, 1983.—559 с.

4. Карташев, А.Л., Сафонов, Е.В., Карташева, М. А. Разработка математической модели установки автономного теплообеспечения на основе солнечного термального коллектора. // Вестник ЮУрГУ, № 34, 2011- с. 61-68. [Электронный ресурс] режим доступа: https://elibrary.ru/

5. Коэффициент отражения $(p, \%)$ при различных углах падения для стекла и воды. [Электронный ресурс] режим доступа: https://tehtab.ru/Guide/ GuidePhysics/LightAndColor/FactorReflection/

6. Азимут и высота солнца над горизонтом [Электронный ресурс] режим доступа: https://planetcalc.ru/320/

7. Географические координаты Хабаровска [Электронный ресурс] режим доступа: https://ru.wikipedia.org/

8. Средняя месячная и годовая температура воздуха, ${ }^{\circ}$ С. РФ. Хабаровский край, [Электронный ресурс] режим доступа: ttps://tehtab.ru/Guide/GuidePhysics/

9. Таблица теплопроводности материалов [Электронный ресурс] режим доступа: https://termoizol.com/polnaya-tablitsa-teploprovodnosti-razlitchnhstroitelynh-materialov.html

10. Теплопроводность и плотность стекла, свойства фарфора, фаянса, хрусталя [Электронный ресурс] режим доступа: http://thermalinfo.ru/svojstva-materialov/ keramika-i-steklo

11. Теплопроводность воздуха в зависимости от температуры и давления [Электронный ресурс] режим доступа: http://thermalinfo.ru/svojstva-gazov/gazovyesmesi/

12. СНиП 23-01-99. Таблица 4 - Суммарная солнечная радиация (прямая и рассеянная) на горизонтальную поверхность при безоблачном небе. МДж/м2. РФ в зависимости от месяца и географической широты. $40-68^{\circ}$ с.ш. Электронный ресурс] режим доступа: https://tehtab.ru/Guide/GuidePhysics/Climate/

(с) Милюков Павел Александрович ( Pavel-milukov@mail.ru ).

Журнал «Современная наука: актуальные проблемы теории и практики»

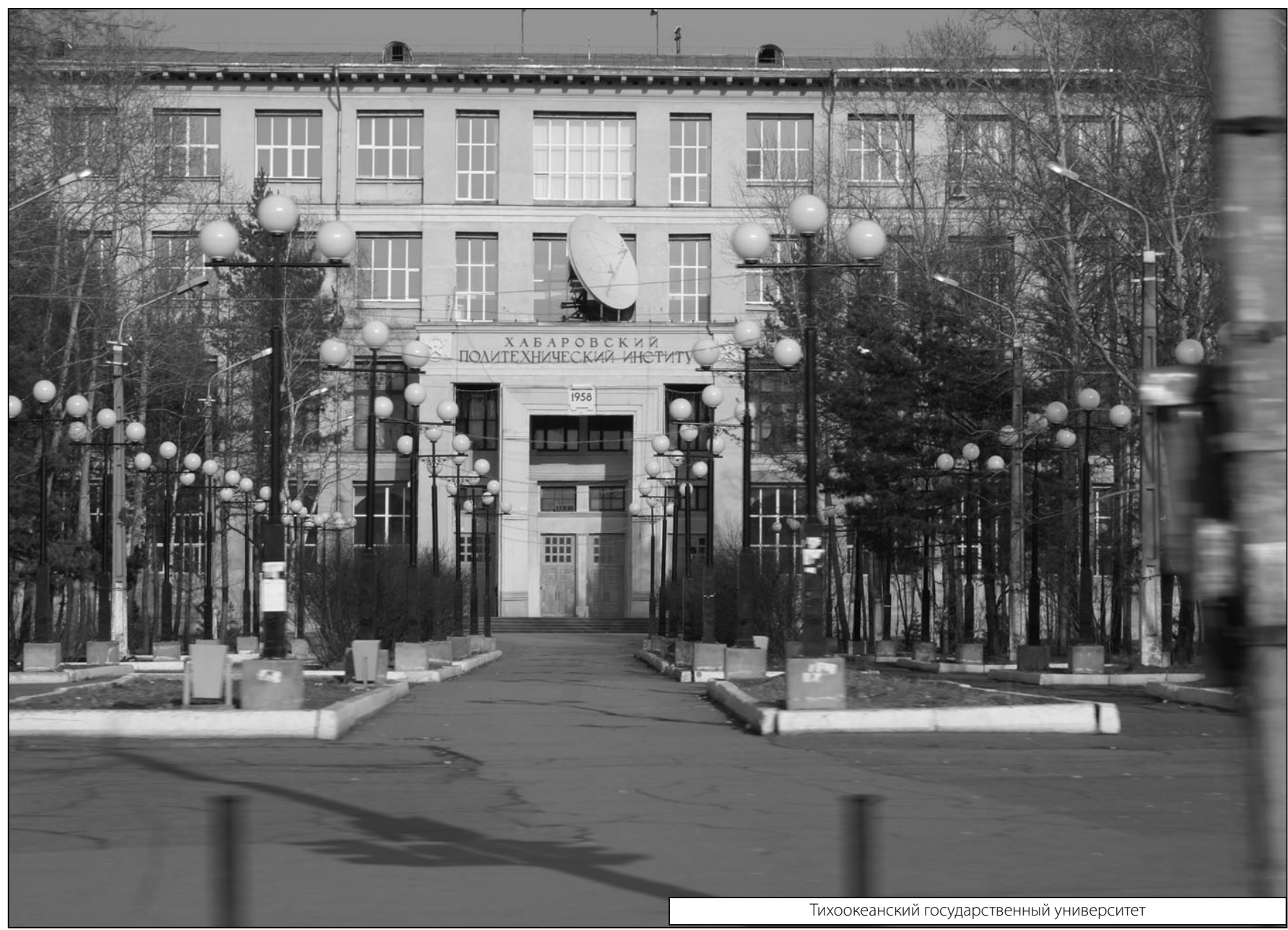

